DOI 10.14526/2070-4798-2018-13-4-134-143

\title{
High class athletes' psychophysical state study during adaptation to the conditions of competitions in terms of Russian Far East
}

\author{
Natalya Yu. Palchikova*, Sergey S. Dobrovolskiy, Victor V. Mezentsev \\ Far Eastern State Academy of Physical Culture, Khabarovsk, Russia \\ Palchikovadvgafk@list.ru*
}

\begin{abstract}
Sports working capacity and a high functional readiness support, at the peak of sports fitness during the flight through several time zones, is an important objective for trainers and doctors of national teams. Specialists mention steady biological rhythms disorder during the flight more than 3 time zones, which is demonstrated in motor, physiological and psycho-emotional reactions violation. In terms of training national teams for the future Games of the Olympiad in Tokyo and Bejing it is interesting to study the processes of athletes' adaptation during the flight from the west to the east and also preliminary acclimatization in terms of Asian-Pacific region (APR). Materials. The regularities and peculiarities of adaptation among highly-qualified athletes to the conditions of Russian Far East. Methods. Information sources analysis and summarizing; video, pedagogical observation, methods of psychophysical state study, express-method "VibraMed", expert analysis of competitive activity, methods of mathematical statistics. Results. Analyzing the results dynamics of boxers' psychophysical state right during the competitive period, we can follow the main individual and group tendencies. Athletes of "A" group are more experienced boxers, who have already taken part in big competitions. Their distinctive feature is a quick CNS functional state adaptation. A new daily rhythm formation was quicker, which can be conditioned by the experience of adaptation during many flights and by more stable state of psycho-emotional sphere in competitive conditions. The athletes' indices of this group in general during the whole time of adaptation changed gradually, in some indices there was the increase at the beginning of the competitions, in comparison with the initial results. All athletes of this group won in the final combats. The studied indices of the athletes from the second group changed quickly, with rough increases, at the same time, the indices didn't achieve the initial level. The athletes from the second group needed longer period for adaptation, as they didn't have time to achieve their optimal psychophysical state towards the beginning of the competitions. The results of the competitive activity of the athletes from "B" group were worse. Conclusion. The results of the held research showed that there are general regularities of adaptation, however, individual peculiarities of adaptation are more important during training for the most important competitions.
\end{abstract}

Keywords: adaptation, athlete, training process, psychophysical state.

For citation: Natalya Yu. Palchikova, Sergey S. Dobrovolskiy, Victor V. Mezentsev. High class athletes' psychophysical state study during adaptation to the conditions of competitions in terms of Russian far east. The Russian Journal of Physical Education and Sport. 2018; 13 (4): 109-117 DOI 10.14526/2070-47982018-13-4-134-143

Sports working capacity and a high functional readiness support, at the peak of sports fitness during the flight through several time zones, is an important objective for trainers and doctors of national teams. The urgent questions of the athletes' time-related adaptation were studied by native and foreign specialists $[2,3,4,5,6]$. Specialists mention steady biological rhythms disorder during the flight more than 3 time zones, which is demonstrated in motor, physiological and psycho-emotional reactions violation.

\section{The objectives of the research:}

- to define the differences of psychophysical state indices during the process of adaptation to the conditions of the Far East among high-class boxers;

- to define the peculiarities of group and individual changes in psychophysical state indices among highly-qualified boxers during adaptation.

\section{Research Methods}

The following complex of research methods was used in the research: 
- information sources analysis and summarizing;

- video taking for competitive activity analysis (the number of accurate blows, combat density and etc.);

- pedagogical observation over the training and competitive process;

- methods of psychophysical state study: hardware and software complex (HSC) "NS-Psikhotest” for orientative-visual-searching reaction analysis according to Shulte-Platonov tables (OVSR), simple visualmotor reaction (SVMR), choice reaction (CR), reactions to a moving object (RMO), attention focusing (AF), voluminal attention (VA). Apart from mentioned above reactions, the indices of coordination and power were registered [12]:

- express-method "VibraMed" [1] for more than 12 psycho-emotional parameters of a person control and diagnostics (aggression, stress, anxiety, tranquility, energy, self-regulation, inhibition and others) [7, $8,9,10,11]$. The methodology of vibroimage analysis helps to study psycho-emotional state of an athlete without interference into the training process, using information-statistical analysis concerning threedimensional head micro motion and vestibular-emotional reflex;

- competitive activity expert analysis;

- methods of mathematical statistics.

12 highly-qualified boxers took part in the research (1 Merited Master of Sports, 2 World-class athletes and 9 masters of sport). The research was held at the beginning and during the Xth International Boxing tournament in memoriam of K. Korotkov. The athletes were examined in the morning.

\section{Results and Discussion}

In order to solve the first objective of the research more than 50 indices (among them we defined the most important ones), which reflect athletes' psychophysical and psycho-emotional state during adaptation were studied (Pictures 1, 2).

The dynamics of psychophysical characteristics analysis showed that the most considerable changes were on the third, sixth and tenth days of adaptation. The most significant changes were in the following indices: simple visual motor reaction on the third day decreased till $9 \%$, on the $6^{\text {th }}$ day increased the initial index till $4 \%$, on the $8^{\text {th }}$ day decreased till $6 \%$ from the initial and at the end of the competitions increased by $2 \%$ from the initial level. The accuracy of orientative-visual-searching reaction was the following: $-6,8 \%$ on the second day; $+12,3 \%$ on the $7^{\text {th }}$ day; $+8 \%$ on the $9^{\text {th }}$ day. Reaction to a moving object became worse on the $3^{\text {rd }}$ day of adaptation by $3,7 \%$, on the $5^{\text {th }}$ day it improved by $3,2 \%$ in comparison with the initial level and on the $10^{\text {th }}$ day it improved by $6,5 \%$. Choice reaction decreased on the $3^{\text {rd }}$ day by $4 \%$, then it improved on the $5^{\text {th }}$ and the $7^{\text {th }}$ day by 3,8 and $6,9 \%$. Dynamometry decreased by $5 \%$ on the $3^{\text {rd }}$ day; on the $6^{\text {th }}$ day it increased $+3,5 \%$.

In psycho-emotional indices there was a wave-like dynamics. Most of all changes were during the $1^{\text {st }}, 5^{\text {th }}, 7^{\text {th }}, 10^{\text {th }}$ days of adaptation.

Aggression decreased by 8\%, then increased till 3\%, then the index achieved the initial level, after that it started to increase from $+29 \%$ and till $+40 \%$ on the $11^{\text {th }}$ day. Energy increased: $5 \% ;+4,5 \% ;+17,2 \%$; $+12 \%$ during the mentioned days. Self-regulation indices changed during the mentioned days by $-8 \%$; $-2,4 \% ;+12 \% ;+7,2 \%$; anxiety indices: $+3 \% ;+8 \% ;+4 \% ;+10 \%$.

Thus, during the $1^{\text {st }}$ and the $3^{\text {rd }}$ days of adaptation there were negative changes of the studied indices, on the $5^{\text {th }}-7^{\text {th }}$ day their values renewed till the initial level and in some cases increased this level.

Individual changes analysis of psychophysical indices revealed considerable differences in the character and the volume of changes. That is why the athletes were divided into two groups $-\mathrm{A}$ and $\mathrm{B}$, according to mentioned above peculiarities of adaptation. 


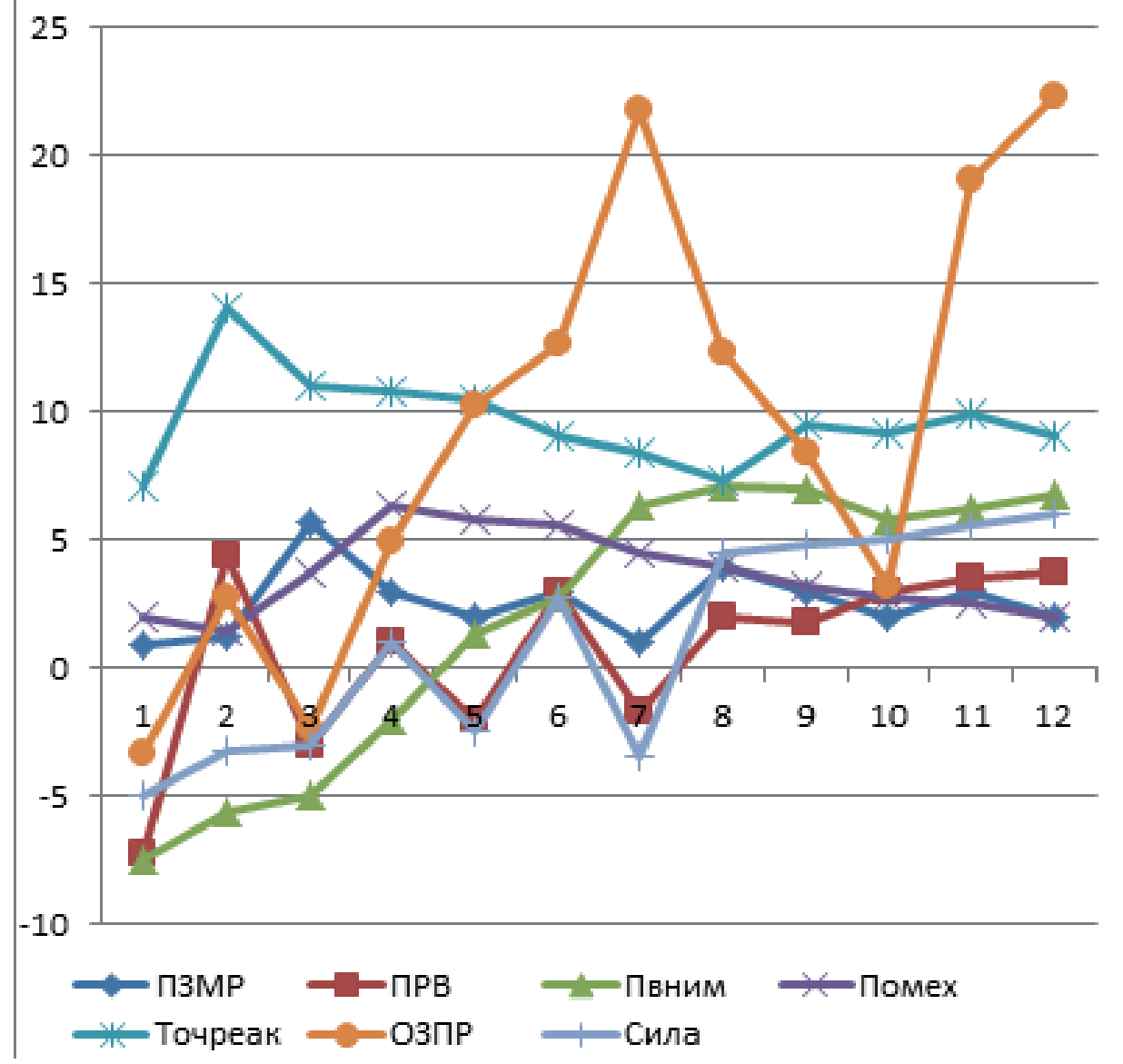

Picture 1 - Indices dynamics of highly-qualified athletes' psychomotor system and power during adaptation

\section{П3MP-SVMR}

ПPВ- choice reaction index CRI

Пвним-Index of attention

Помех- noise stability

Точреак- accuracy of reaction

O3חP-OVSR

Сила-power

Comparative analysis of the studied indices revealed group characteristics of adaptation (table 1). During the test the athletes from "A" group had the following simple visual-motor reaction index: $207 \mathrm{~ms}$, which corresponds with the average speed of sensomotor reaction. During the $1^{\text {st }}$ day of adaptation the index was $209 \mathrm{~ms}$ (the average speed of sensomotor reaction). The peak of this index increase till $199 \mathrm{~ms}$ (high speed of sensomotor reaction) was during the $3^{\text {rd }}$ day of adaptation. On the $10^{\text {th }}$ and the12th day of adaptation the index was 199 and $197 \mathrm{~ms}$ (high speed of sensomotor reaction).

The index of choice reaction (ms), stated during the test, in the average was $318 \mathrm{~ms}$ (high speed of sensomotor reaction). During the $1^{\text {st }}$ day of adaptation the index was $341 \mathrm{~ms}$ (the average speed of sensomotor reaction). The peak of increase till $304 \mathrm{~ms}$ (high speed of sensomotor reaction) was during the $2^{\text {nd }}$ day of adaptation, the peak of decrease was on the $9^{\text {th }}$ day of adaptation and was $371 \mathrm{~ms}$, on the $12^{\text {th }}$ day of adaptation $-369 \mathrm{~ms}$ (the average speed of sensomotor reaction).

The index of attention estimation (ms), registered during the test, in the average was $294 \mathrm{~ms}$ (transitional type between the inert and non-stationary type of higher nervous activity). During the first day of adaptation the index was $316 \mathrm{~ms}$ (inert type of higher nervous activity). There was no quick decrease of this index during the test. The peak of increase was during the $9^{\text {th }}$ day $-273 \mathrm{~ms}$, during the $12^{\text {th }}$ day 
of adaptation - $276 \mathrm{~ms}$ (transitional type between the inert and non-stationary type of higher nervous activity).

Noise stability index (ms), registered during the test, in the average was $363 \mathrm{~ms}$ (inert type of higher nervous activity). During the $1^{\text {st }}$ day of adaptation the index was $353 \mathrm{~ms}$, which corresponds with the inert type of higher nervous activity. The peak of decrease was during the $4^{\text {th }}$ day of adaptation $-386 \mathrm{~ms}$, and during the $5^{\text {th }}$ day $-394 \mathrm{~ms}$. This index improvement was during the $6^{\text {th }}$ day of adaptation - till $342 \mathrm{~ms}$, and during the $9^{\text {th }}$ day $-346 \mathrm{~ms}$ (transitional type between the inert and non-stationary type of higher nervous activity). On the $12^{\text {th }}$ day of adaptation this index was $360 \mathrm{~ms}$ (inert type of higher nervous activity).

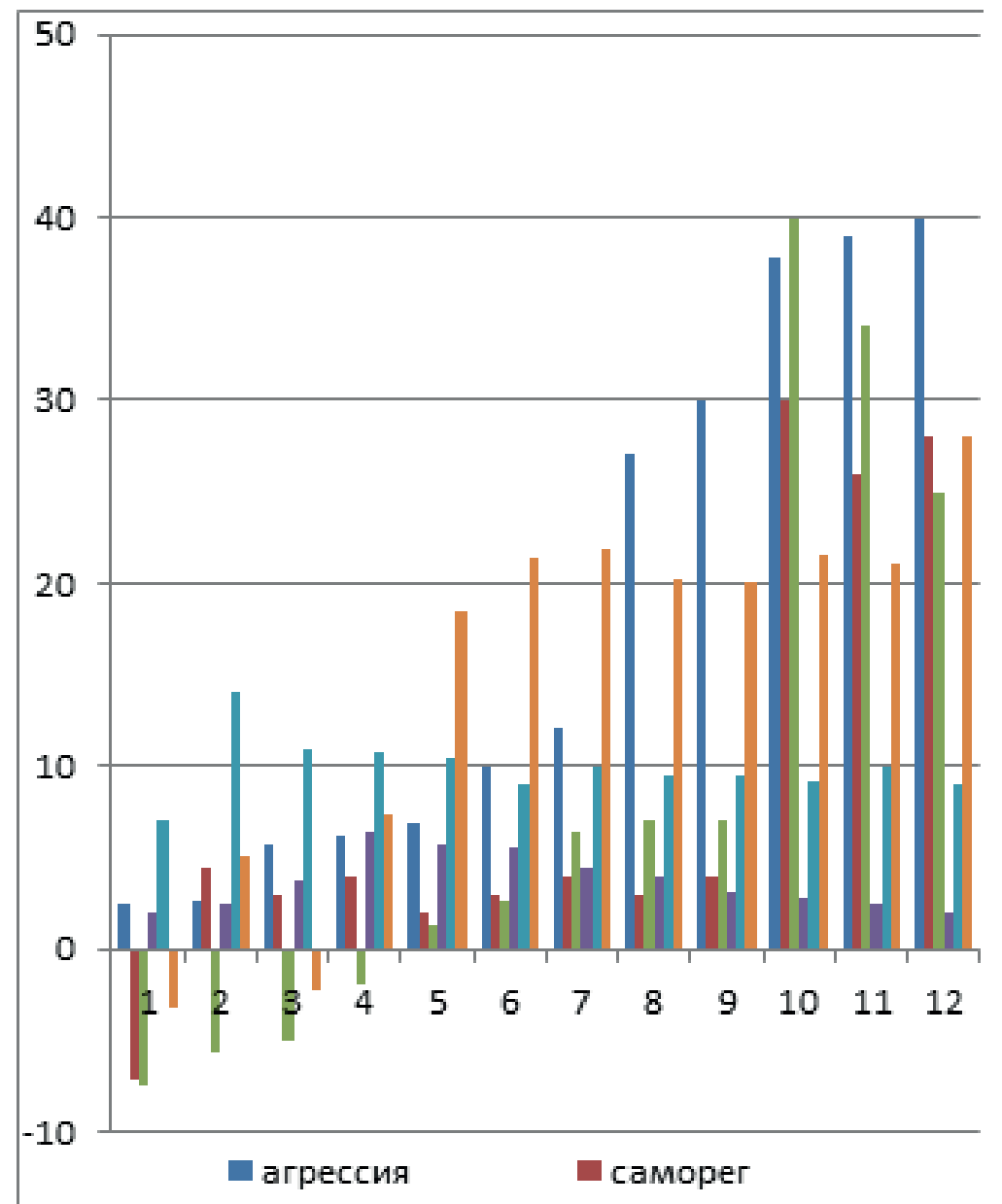

Picture 2 - Indices dynamics of highly-qualified athletes' psycho-emotional state during adaptation

Агрессия-aggression caмoper-self-regulation энергичность-energy невротизм- neuroticism тревожность-anxiety пси-energetics

The index of accuracy of reactions (quantity) in the reaction to a moving object, registered in the test, in the average was 14 (70\%) (the average level of accuracy of reactions). During the $1^{\text {st }}$ day this index was $13(65 \%)$ (the average level of reactions accuracy). There was no quick decrease of this index during the test, but maximum values were registered during the $2^{\text {nd }}$ and the $3^{\text {rd }}$ days of adaptation - till 16 (80\%) (above the average level of reactions accuracy). During the $12^{\text {th }}$ day of adaptation this index was 12 (60\%) (the average level of reactions accuracy). 


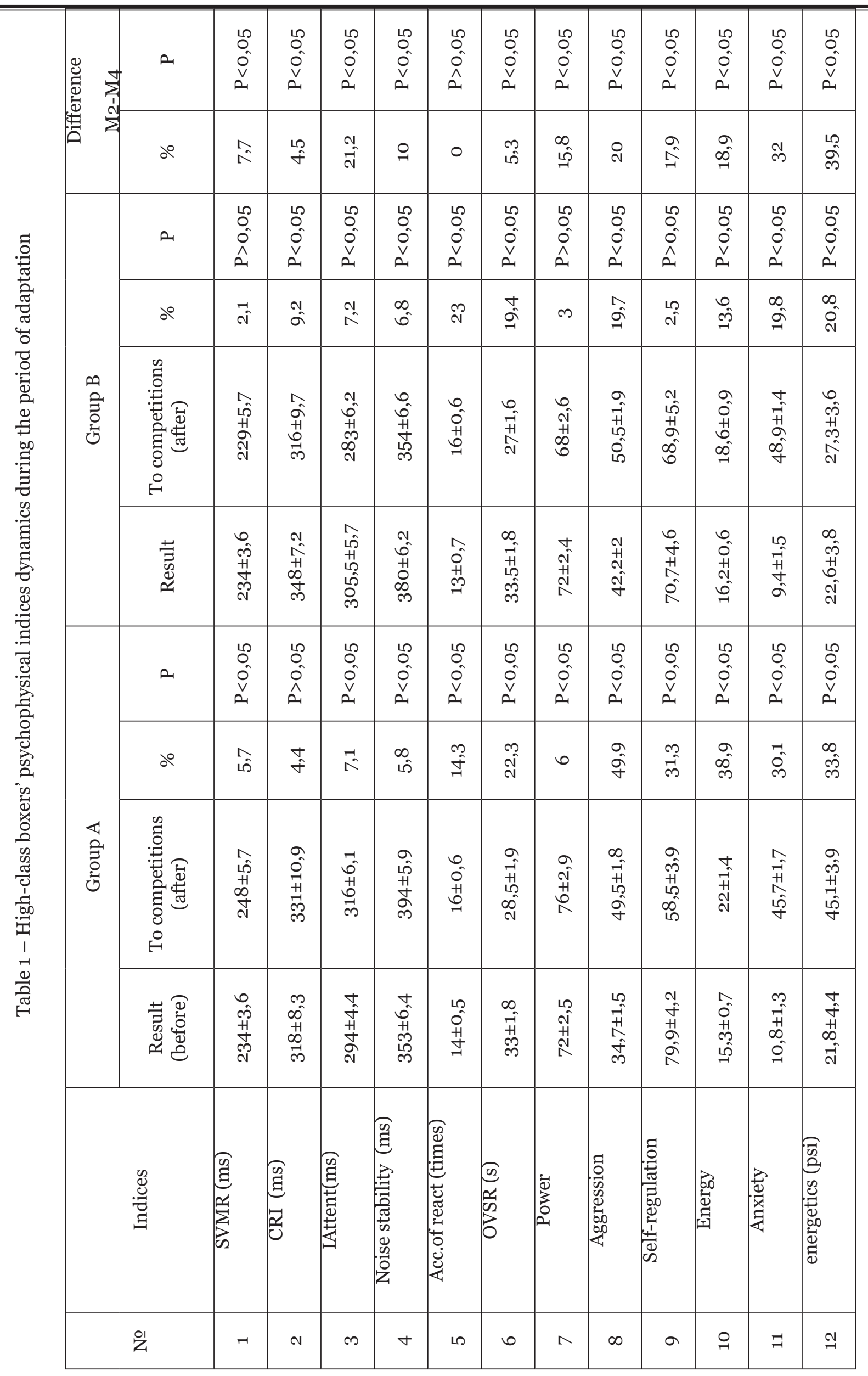


Simple visual reaction index (s.), registered during the test, in the average was 33 seconds (above the average index). During the $1^{\text {st }}$ day of adaptation it was 44,5 seconds, which corresponds with the average value. There was this index decrease during the whole test, but the highest values were registered on the $5^{\text {th }}$ day of adaptation $-26,5$ seconds, on the $9^{\text {th }}$ day of adaptation -29 seconds (high index); on the $12^{\text {th }}$ day of adaptation the index of simple visual reaction $P$ was 28,5 seconds (high index).

Taking into consideration the dynamics of psycho-emotional indices of A group athletes we come to the following conclusion. The main indices changes had a stable character. Since the $1^{\text {st }}$ till the $3^{\text {rd }}$ day "aggression", "danger", "tranquility" (everything within $8 \%$ from the initial level) decreased. Since the $3{ }^{\text {rd }}$ till the $5^{\text {th }}$ day there was "aggression" increase $-18 \%$, "self-regulation" - till 19\%, "tranquility" - till 10\%, "energy" -till 20\%, "anxiety", "inhibition,", "neuroticism" indices decreased by 8, 5 and $12 \%$. The main "negative peak" of these boxers' adaptation after coming to Far East was relatively stable, not causing big leaps in psycho-emotional indices. Then there was the tendency of "aggression" increase till $19,2 \%$ on the $6^{\text {th }}$ day, "charisma"-till 29,6\%, "self-regulation" till 16,7\%, which can be explained by the orientation of an athlete to the coming competitions. "Stress" level decreased within 17,3\%, "integral positive index" increased till 10\%, "energy" increased till 12,3\%, which could be caused by the main processes of competitive combats, there was general tendency to the following indices increase: "tranquility"(till 22,8\%), "energy"(till 81\%), "selfregulation"(till 24\%), "integral positive indices"(till 72\%), "energy consumption”(till 15\%). The following indices stably decreased: "stress" (till 17,3\%), "anxiety" (till 21\%), "inhibition” (till 22\%), "energy"(till 19\%). The sleep of athletes wasn't almost disturbed after the flight. The first three days athletes got up very early, then their sleep stabilized. Taking into consideration high qualification of the athletes, it can be said that they felt psychological comfort quickly enough after the flight, psychophysiological functions of an organism stabilized on the $4^{\text {th }}$ day, time-related adaptations were quick enough.

The athletes from "B" group had the following index of simple visual-motor reaction (ms), during the whole time of test: in the average $211,5 \mathrm{~ms}$ (the average speed of reaction). During the $1^{\text {st }}$ day of adaptation the index was $210 \mathrm{~ms}$ (the average speed of sensomotor reaction). The peak of increase till $190 \mathrm{~ms}$ - a high speed of sensomotor reaction - was during the $6^{\text {th }}$ day of adaptation and on the $12^{\text {th }}$ day $-196 \mathrm{~ms}$ (high speed of reaction). The peak of decrease was during the $2^{\text {nd }}$ day of adaptation - till $230 \mathrm{~ms}$ (a low speed of reaction). On the $13^{\text {th }}$ day of adaptation this index was almost equal to the initial value $-211 \mathrm{~ms}$ (the average speed of sensomotor reaction).

Choice reaction index (ms), registered during the test, in the average was $348 \mathrm{~ms}$ (the average speed of sensomotor reaction). During the $1^{\text {st }}$ day of adaptation the index was $364 \mathrm{~ms}$ (the average speed of sensomotor reaction). The peak of improvement till $316 \mathrm{~ms}$ was during the $2^{\text {nd }}$ day of adaptation and during the $13^{\text {th }}$ day $-322 \mathrm{~ms}$ (high speed of reaction). The peak of decrease was during the $9^{\text {th }}$ day of adaptation and was $381 \mathrm{~ms}$ (the average speed of reaction).

Attention estimation index (ms), registered during the test, in the average was 305,5 ms (inert type of higher nervous activity). During the $1^{\text {st }}$ day of adaptation the index was $313 \mathrm{~ms}$, which corresponds with inert type of higher nervous activity. The peak of worsening was during the $2^{\text {nd }}$ day of adaptation -323 $\mathrm{ms}$. The peak of this index improvement till $283 \mathrm{~ms}$ was during the $6^{\text {th }}$ day of adaptation, on the $8^{\text {th }}$ day of adaptation -287 ; during the $13^{\text {th }}$ day of adapatation the index was $298 \mathrm{~ms}$ (transitional type between the inert and non-stationary type of higher nervous activity).

The index of noise stability (ms), registered during the test, since May, 7 till May, 19, in the average was $380 \mathrm{~ms}$ (inert type of higher nervous activity). During the $1^{\text {st }}$ day of adaptation this index was $461 \mathrm{~ms}$, which corresponds with the inert type of higher nervous activity. In general there was this index decrease during the test. The peak of decrease was on the $6^{\text {th }}$ day of adaptation $-354 \mathrm{~ms}$ and on the $8^{\text {th }}$ day $-330 \mathrm{~ms}$ (transitional type between the inert and non-stationary type of higher nervous activity). During the $13^{\text {th }}$ day of adaptation the index of noise stability decreased in comparison with the initial value (461ms) till $362 \mathrm{~ms}$ (till 99ms) (inert type of higher nervous activity). 
The accuracy of reactions index (times) in the reaction to a moving object, registered during the test, in the average was 13 (65\%) (the average level of reactions accuracy). During the $1^{\text {st }}$ day of adaptation this index was 13 (65\%) (the average level of reactions accuracy). During the $3^{\text {rd }}$ and the $4^{\text {th }}$ day of adaptation (May, 9-10) the index was 16-17 (80-85\%) (above the average - high level of reactions accuracy); during the $10^{\text {th }}$ day of adaptation the index was 16 (80\%) (above the average the level of reactions accuracy). During the $12^{\text {th }}$ and the $13^{\text {th }}$ days of adaptation there was accuracy of reactions decrease till 13 times (the average level of reactions accuracy coinciding).

The index of simple visual-motor reaction (s), registered during the test, in the average was $33,5 \mathrm{~s}$ (above the average index). During the $1^{\text {st }}$ day of adaptation this index was $44 \mathrm{~s}$, which corresponds with the average value. In general, there was this index gradual decrease. The peak of index improvement till $27 \mathrm{~s}$ was during the $6^{\text {th }}$ and the $10^{\text {th }}$ days of adaptation and during the $12^{\text {th }}$ day $-26 \mathrm{~s}$ (high index). During the $13^{\text {th }}$ day of adaptation there was this index worsening till $38,5 \mathrm{~s}$.

In B group there was the following indices decrease: "aggression", "danger", "tranquility" since the $1^{\text {st }}$ till the $3^{\text {rd }}$ day (within 15,5 and $10 \%$ ). Also there was a quick decrease of the following indices on the $3^{\text {rd }}$ day of adaptation among B group athletes: "energy"- more than $16 \%$, "self-regulation" - till 24,3\%, "charisma" till 29,6\%, "integral positive" and "physiological" indices till 18\%. Stable enough were the following indices: "inhibition", "energy consumption", "integral negative" with the spread of no more than $8 \%$. The athletes felt worse during the $3^{\text {rd }}$ day on arriving in Far East. There were sleep disorders (they started to fall asleep later and woke up earlier). Subjective feelings of the athletes also become worse: they were tired, had the symptoms of cold, had dull mood. The athletes complained of bad sleep, the duration of sleep decrease, the absence of a good night's sleep. Drowsiness and weakness was in the morning. During late evening hours psycho-emotional and motor activities distinctly increased. Since the $3^{\text {rd }}$ till the $5^{\text {th }}$ day there was "aggression" increase till $38,6 \%$, "tranquility" increase till $10,3 \%$, "energy" increase till 8\%, "anxiety", "inhibition", "neuroticism" indices also increased till 10, 5 and $5 \%$. Then since the $6^{\text {th }}$ till the $12^{\text {th }}$ day, including the days of competitive combats, the dynamics was the following: the tendency of the following indices decrease "tranquility" (till12\%), "energy" (till 31\%), "self-regulation" (till $10 \%$ ), "integral positive indices" (till 10\%), "energy consumption" (till 15,7\%). The following indices had a stable increase: "stress" (till 10\%), "anxiety" (till 20\%), "inhibition" (till 5\%), "energy" (till 20\%). The following indices decreased: "anxiety”, "neuroticism”, "physiological and integral negative" (till 1o points), "energy" decreased till 30\%. Stable enough were the following indices: "energy consumption", "aggression", "charisma", "self-regulation". The following indices increased: "stress" till 15\%, "danger" till 5\%, "energy" till 20\%. Also the following indices distinctly increased: "danger" till 35 points, "inhibition" till 10 points, "neuroticism" till 25 points. The tendency decrease was in the following indices: "energy consumption" (till 30 points), "tranquility" (till 20 points), "self-regulation" (till 20 points), "integral positive indices" - till 15 points, "physiological" - till 20 points. The most variative indices in this group are the following: "aggression" - the spread from the beginning till the end of the competitions was 40 points, "energy" - the spread was till 30 points, "charisma" and "energy" -till 25 points.

The changes of the other indices of psycho-emotional state were minimal. The points spread was only till 10 points, which is insignificant, in the opinion of the methodology authors.

Any irregularity in "aura" color and size characterizes the object's movement and psychophysiological state. A normal state of a person is characterized by more equal outer vibroimage (vibro-aura), blue, green, violet prevail $[12,13,14]$. The athletes from "A" group demonstrated more stable "aura" silhouette, bluegreen colors prevail.

For a tense state of a person great space and color vibro-aura irregularity is typical, which was among the athletes from "B" group.

During the indices comparison among the athletes from two groups it was revealed that the athletes from "A" group turned out to be more stable in adaptation to negative factors (acclimatization, fatigue, 
trauma, cutting weight and etc.), which is presented in table 1 . The most significant differences to the end of the adaptation period (competitive) were in the following indices: among " $\mathrm{B}$ " group athletes, in comparison with "A" group athletes, high indices turned out to be the following: attention estimation index - by $21,2 \%$ $(\mathrm{P}<0,05)$; SVMR - by 7,7\% $(\mathrm{P}<0,05)$; noise stability index - by $10 \%(\mathrm{P}<0,05)$; which proves less activity of nerve processes, high level of visual-motor centers fatigue. In dynamometry indices "A" group athletes had the increase by $15,8 \%(\mathrm{P}<0,05)$. Low lability of nerve processes had a negative influence on coordination and power abilities of "B" group athletes.

In psycho-emotional sphere demonstration "A" group boxers turned out to be more adaptive. "Selfregulation" index among the athletes from this group turned out to be $17,9 \%(\mathrm{P}<0,05)$ higher, than among "B" group athletes, "energy" index turned out to be $18,9 \%(\mathrm{P}<0,05)$ higher; a complex index of energy turned out to be $39,5 \%(\mathrm{P}<0,05)$ higher; "aggression" of "A" group athletes increased by $20 \%(\mathrm{P}<0,05)$.

Other psychophysical indices changed statistically not significantly.

All mentioned above influenced sports result of the definite boxers, most indices of competitive activity among "A" group athletes were considerably higher than the indices of "B" group athletes. The following group tendencies were demonstrated: the number of accurate strikes increased by $10 \%$ among "A" group athletes; the coefficient of attack efficiency increased by $12 \%$; the index of "tactical objectives solution during the combat" improved by $15 \%$. The final combats among "A" group boxers were held in a quick tempo, strictly attacking manner, mainly at mid and close distances. Among "B" group athletes the following indices decreased: power, energy, energy consumption and it influenced competitive activity.

Analyzing the results dynamics of boxers' psycho-emotional state directly during the competitions, we can see the main individual and group tendencies.

\section{Conclusion}

Thus, it should be noted that "A" group athletes are more experienced boxers, who took part in big competitions and who won at the present competitions. Their distinctive feature is a quick adaptation of CNS functional state. A new daily rhythm formation was quicker, which can be conditioned by the experience of adaptation in terms of great number of flights and by more stable psycho-emotional sphere state in terms of competitive conditions. The athletes' indices from this group changed gradually and equally during the whole period of adaptation, in some indices there was some increase at the beginning of competitions in comparison with the initial results. All athletes of this group won the final combats.

The studied indices of the second group athletes changed quickly, with rough increases, at the same time, the indices didn't achieve the initial level. The second group athletes needed longer period for adaptation, as they didn't have time to achieve their optimal psychophysical state towards the beginning of the competitions. The results of the "B" group athletes competitive activity were worse.

\section{References}

1. Minkin V.A., Nikolaenko N.N. The technology and system of vibroimage use for motor activity analysis and a functional state of an organism study. Medicinskaya tehgnika. 2008; 4: 30-34 (in Russ.).

2. Iordanskaya F.A., Usakova N.A., Suslov F.P., Shreyberg G.L., Solovev V.A. Desynchronosis correction during the flight to the west and east. Nauchno-sportivnyj vestnik. 1988; 3: 23-27 (in Russ.).

3. Gulherme Bresciani, Maria J. Cuevas, Nuria Garatachea, Olga Molinero, Mar almar, Jose A. De Paz, Sara Marquez, Javier Gonzalez-Gallego. Monitoring biological and psychological measures throughout an entire season in male handball players. European Journal of Sport Science. 2010; 10(6): 377-384. DOI 10.1080/17461391003699070.

4. Ronglan L.T., Raastad T., Borgesen A. Neuromuscular fatigue and recovery in elite female handball players. Scandinavian Journal of Medicine and Science in Sports. 2006; 16: 267-275.URL: https://www.researchgate.net/publication/6890711 Neuromuscular fatigue and recovery in elite female handball players.

5. Barron K.E., Harackiewics J.M. Achievement goals and optimal motivation: Testing multiple goal models. Journal of Personality and social Psychology. 2001; 80(5): 706-722. DOI 10.1037/0022- 
$3514.80 .5 \cdot 706$.

6. McNeill M.C., Wang J.C.K. Psychological profiles of elite school sports players in Singapore.

Psychology of Sport and Exercise. 2005; 6(1): 117-128. DOI 10.1016/j.psychsport.2003.10.004.

7. Nicholls J.G. Achievement motivation: Conceptions of ability, subjective experience, task choice, and performance. Psychological Review. 1984; 91(3): 328-346. DOI 10.1037/oo33-295X.

8. Ntoumanis N. Empirical links between achievement goal theory and self-determination theory

in sport. Journal of Sports Sciences. 2001; 19(6): 397-409. DOI 10.1080/026404101300149357.

9. Gert-Jan De Brujin, Bas Van Den Putte. Exercise promotion: An integration of exercise self-

identity, beliefs, intention, and behavior. European Journal of Sport Science. 2012; 12(4): 354-366. URL:

http://dx.doi.org/10.1080/17461391.2011.568631.

10. Biddle S.J.H., Nigg C.R. Theories of exercise behavior. International Journal of Sport

Psychology. 2000; 31: 290-304. URL: https://www.researchgate.net/publication/232534883 Theories of exercise behavior.

11. De Brujin G.J., De Groot R., Van den Putte B., Rhodes R.E. Conscientiousness, extroversion, and action control: Comparing moderate and vigorous physical activity. Journal of Sport and Exercise Psychology. 2009; 31: 724-742.

12. Frazier P.A., Tix A.P., Barron K.E. Testing moderator and mediator effects in counseling psychology research. Journal of Consulting Psychology. 2004; 51: 115-134.

13. Gould D., Dieffenbach K., Moffett A. Psychological characteristics and their development in Olympic Champions. Journal of Applied Sport Psychology. 2002; 14: 172-204.

14. Uphill M.A., Jones M.V. Antecedents of emotions in elite athletes: A cognitive motivational relational perspectives. Research Quarterly for Exercise and Sport. 2007; 78: 79-89.

15. Vast R.L., Young R.L., Thomas P.R. Emotions in sport: Perceived effects of attention, concentration and performance. Australian Psychologist. 2010; 45: 132-140.

\section{Submitted: 10.10.2018}

Author's information:

Natalya Yu. Palchikova* - Candidate of Pedagogics, Far Eastern State Academy of Physical Culture, Amurskij blv., House 1, Khabarovsk, Russia, 680ooo, e-mail: Palchikovadvgafk@list.ru*

Sergey S. Dobrovolskiy - Doctor of Pedagogics, Far Eastern State Academy of Physical Culture, Amurskij blv., House 1, Khabarovsk, Russia, 680ooo, Khabarovsk, Russia

Victor V. Mezentsev - Candidate of Pedagogics, Far Eastern State Academy of Physical Culture, Amurskij blv., House 1, Khabarovsk, Russia, 680ooo, Khabarovsk, Russia 